\title{
Carbon Sink Conservation and Global Justice: Benefitting, Free Riding and Non-compliance
}

\author{
Fabian Schuppert ${ }^{1}$
}

Published online: 24 December 2015

(C) The Author(s) 2015. This article is published with open access at Springerlink.com

\begin{abstract}
It is often assumed that in order to avoid the most severe consequences of global anthropogenic climate change we have to preserve our existing carbon sinks, such as for instance tropical forests. Global carbon sink conservation raises a host of normative issues, though, since it is debatable who should pay the costs of carbon sink conservation, who has the duty to protect which sinks, and how far the duty to conserve one's carbon sinks actually extends, especially if it conflicts with other duties one might have. According to some, forested states like Ecuador have a duty to preserve their tropical forests while the rich states of the global North have a duty of fairness to compensate states like Ecuador for the costs they incur. My aim in this paper is to critically analyse this standard line of argument and to criticise its validity both internally (i.e. with regard to its normative conclusion based on its premises) and externally (i.e. with regard to the argument's underlying assumptions and its lack of contextualisation). As I will argue, the duty to conserve one's forests is only a particular instantiation of a wider, more general duty to contribute towards global climate justice for which the context in which one operates (e.g. whether other agents are complying with their duties of global climate justice or not) matters significantly.
\end{abstract}

Keywords Climate justice $\cdot$ Global justice $\cdot$ Non-compliance $\cdot$ Free riding . Yasuni · Fairness

Fabian Schuppert

f.schuppert@qub.ac.uk

1 Queen's University Belfast, Belfast, UK 


\section{Introduction}

Global anthropogenic climate change is real and its consequences across the globe are expected to be for the most part harmful and adverse. Amongst climate and environmental scientists it is widely agreed that in order to successfully tackle anthropogenic climate change and increasing biodiversity loss we have to-among other things-govern and manage our available stock of natural resources differently. With regard to the dangers of climate change, it seems particularly important to conserve and protect major carbon sinks, such as for instance tropical rainforests, which are not only a major carbon sink but also major long-term carbon repositories. Tropical forests are estimated to hold anywhere between 220 billion tonnes of carbon (UNFAO 2010) and up to 247 billion tonnes of carbon (NASA 2011), with the tropical forests in Central and Latin America accounting for almost $50 \%$ of all carbon stored in tropical forests. ${ }^{1}$ Globally, forests store around 652 billion tonnes of carbon, which dwarfs the estimated 337 billion tonnes of carbon which have been released into the atmosphere because of fossil fuel consumption and cement production since 1751 (Boden et al. 2010). It is because of their vital function within the global carbon cycle that tropical forests have been identified as a key carbon sink which needs to be preserved if the states of this world want to have any chance of reaching their goal of keeping global temperature rise below $2{ }^{\circ} \mathrm{C}$. Therefore, it is often assumed that forested states have a duty of global climate justice to conserve their forests. ${ }^{2}$

Global carbon sink conservation raises a host of normative issues, though, since it is for instance debatable who should pay the costs of carbon sink conservation, who has the duty to protect which sinks (especially since not all sinks are terrestrial) and how far the duty to conserve one's carbon sinks actually extends (e.g. is it morally impermissible to cut down a small part of one's forests if that creates major benefits for the local population?). ${ }^{3}$ These normative questions are not just of a purely theoretical nature. When Ecuador discovered major oil reserves under the area of the Yasuni national park in Eastern Ecuador, the government of Ecuador founded the Yasuni Ishpingo-Tambococha-Tiputini Initiative (Yasuni ITTI), which asked foreign governments, non-governmental organisations and individual stakeholders to pay into a fund for the conservation of the Yasuni national park. If by 2023 the fund were able to generate donations of around US\$3.6 billion, Ecuador would leave the oil reserves in the ground; if not, Ecuador would go ahead and extract the oil. The rationale behind the Yasuni ITTI was clear, Ecuador would preserve parts of its crucial global carbon sinks (and of the park's amazing biodiversity), but the

\footnotetext{
1 Measuring the carbon stock of the world's tropical forests is extremely difficult and complex. For an overview of different methodologies and their varying results see Gibbs et al. (2007).

2 This is not to say that only forested states have duties of global climate justice. Instead it simply expresses the idea that those states in whose territories certain carbon sinks are found are primarily responsible for preserving them as part of their duties of global climate justice.

3 While this introduction deals with the issue of carbon sink conservation as such, the main argument of this paper will deal with the conservation of tropical forests only. The reason for this is that the standard argument I criticise has this very same focus. However, in sections three and four I will briefly highlight some problems concerning this extremely narrow focus of the standard argument.
} 
costs of doing so (both direct and indirect) would have to be borne by foreign governments and other parties. ${ }^{4}$ In August 2013, the Yasuni ITTI was declared unsuccessful, due to insufficient contribution to the UN-administered fund.

While the Yasuni ITTI was politically controversial, it provides a welcome real world background for the philosophical arguments concerning the ethics of carbon sink conservation, which I am concerned with in this paper. Within the philosophical literature a standard argument for the duties involved in carbon sink conservation exists, which nicely mirrors some of the claims advanced by the government of Ecuador. The standard argument, which has been most skilfully explicated by Chris Armstrong (2015a, c), holds that while Ecuador has a duty of justice to conserve its tropical forests, the developed states of the global North have a duty to bear (most of) the costs of doing so. ${ }^{5}$ My aim in this paper is to critically analyse the standard argument and to criticise its validity both internally (i.e. with regard to its normative conclusion based on its premises) and externally (i.e. with regard to the argument's underlying assumptions and its lack of contextualisation). ${ }^{6}$ As I will argue, because the duty to conserve one's forests is only a particular instantiation of a wider, more general duty to contribute towards global climate justice, the context in which one operates (e.g. are other agents complying with their duties of global climate justice or not) matters significantly.

The paper is structured as follows: in section one, I will introduce the standard argument for carbon sink conservation and its associated duties in more detail. Section two, then, offers two possible interpretations of the standard argument, namely, one based on the beneficiary pays principle (BPP) and one based on the principle of fairness $(\mathrm{PoF})$. As I will argue, both interpretations face serious issues and seem ill-equipped to convincingly show why the developed states of the global North should bear most of the costs for carbon sink conservation. Section three will contextualise the standard argument and carefully unpack the duties involved and how these might change in a world of non-compliance, while raising some issues of taking as narrow an angle as the standard argument. In so doing, I hope to show that the ethics of carbon sink conservation has to be embedded in a wider analysis of what climate justice requires and how duties change (or not) under non-ideal circumstances.

\section{The Standard Argument}

Before I introduce the standard argument in more detail, let me briefly highlight some caveats with regard to the arguments presented in this paper.

First, both the standard argument and my criticism thereof will take the national resource privilege, that is, the internationally recognized norm of national sovereignty over natural resources for granted. While the national resource privilege is normatively controversial, this paper cannot and will not engage in a

\footnotetext{
${ }^{4}$ I will come back to the distinction between direct and indirect costs when discussing the standard argument.

5 Both of these duties could be construed as part of states' duties of global climate justice, which is a point I will return to below.

6 Ed Page (2016, in this special issue) also offers a critique of Armstrong's argument. However, while we agree in some of our criticisms, Page focuses exclusively on the issue of cost-sharing.
} 
debate about the privilege's validity, since this would lead too far and it has already been done elsewhere (Armstrong 2015b; Schuppert 2014).

Second, the arguments in this paper will operate on the level of states and peoples, that is to say, the duties of justice and responsibilities I will discuss will refer to states and their people. This is not to deny that individuals might have important duties of global climate justice, too, but since the standard argument focuses on states and their people, I do the same. Moreover, since decisions such as whether a state allows for the exploitation of its natural resources (or not) are normally decisions made by governments and since global climate change is an issue that-at least in part-needs to be solved on the global level, it seems plausible to look at states and their duties first, even if ultimately the duties involved could be either further disaggregated onto or supported by duties on the individual level.

Third, for most of my argument I will follow the standard argument in dividing the world into developing states, some of which are home to large tropical forests, and developed states, which are historically the main contributors of global carbon emissions. This is obviously a rather crude division of the world and not wholly accurate. Therefore, as my argument progresses I will flag up necessary additions to this somewhat simplistic view of the world.

Keeping these points in mind, let me turn to explicating the standard argument, which - as mentioned before-is probably most skilfully defended by Armstrong (2015a, c), although other versions exist [e.g. a more general account based on individual duties provided by Vanderheiden (2014)], while the general idea that developing countries might have duties to preserve their forests, but that they can expect financial support from other countries also underlies schemes such as UNREDD and UN-REDD ${ }^{+}$.

The standard argument takes the following form:

(1) Developing states with major tropical forests have a duty of justice to preserve these forests due to their status as a major global carbon sink, which is a collective good.

(2) There are costs associated with preserving tropical forests, both direct ones (i.e. the costs of actual upkeep, monitoring and enforcement) and indirect ones (e.g. opportunity costs, for instance for countries like Ecuador who forgo the benefits of exploiting the oil reserves underneath the Yasuni national park).

(3) The developed states of the global North (and their people) largely benefit from carbon sink conservation.

(4) Therefore, developed countries have a duty of fairness to bear (a large part of) the costs of tropical forest preservation.

\footnotetext{
7 The UN-REDD program is the United Nations' collaborative initiative on Reducing Emissions from Deforestation and forest Degradation (REDD) in developing countries. REDD ${ }^{+}$further includes the role of conservation, sustainable management of forests and enhancement of forest carbon stocks (UNREDD). For an empirical study testing people's willingness in the UK and Italy to pay for forest conservation in Amazonia, which claims that such schemes could prove popular see Horton et al. (2003).
} 
Depending on where one puts the normative emphasis, the standard argument allows for two different interpretations, one which focuses on the idea of benefitting and that it is beneficiaries who should pay for part of the costs of rainforest protection (I call this the Beneficiary-Pays Argument), and one which focuses on the idea that certain benefits one accrues might trigger a duty of fairness to contribute to the costs of the benefit creation so as to avoid moral free-riding (I call this the FreeRiding Argument). Both interpretations seem intuitively plausible, since the standard argument leaves it open whether it is all beneficiaries simpliciter that should pay, or whether there are certain further conditions which are necessary so as to connect the idea of benefitting in step (3) with the principle of fairness (PoF) in step (4). However, as I argue below, at the end of the day, both interpretations prove problematic. In fact, neither interpretation seems to be able (without further supporting arguments) to provide convincing evidence for the conclusion that developed states of the global North should bear (most of) the costs of carbon sink conservation.

In fact, there is third possibility, namely, to see both the duty to protect the tropical forests as well as the duty to pay for doing so as part of states' duties of global climate justice. However, while this seems plausible and compatible with the arguments I present in this paper, it is not the way the standard argument frames the issue. Thus, for the time being, let us focus on the standard argument and the two ways in which it can be interpreted.

\section{Two Interpretations of the Standard Argument}

\section{The Beneficiary-Pays Argument}

The Beneficiary-Pays Argument adopts the beneficiary pays principle (BPP), one of the most widely used principles in the climate justice literature. In its crudest form, the BPP simply holds that those who benefit from a particular action should pay for the costs associated with the action in question. In this crude form, though, the BPP is not particularly convincing, since mere benefitting does not seem normatively weighty enough to trigger a duty of compensation. Imagine the following case: A and B share a flat. A bakes a cake, because A enjoys baking cakes. Since A cannot eat the entire cake B gets offered by A to eat half the cake. B accepts the offer and eats half the cake. Does from that follow a duty for B to compensate A for half of the costs of baking the cake? This seems doubtful. Of course, A could have asked B to pay for part of the costs of baking the cake while offering the cake, but that is a very different scenario, since the actual benefit for B (i.e. getting to eat half the cake) only materialises if $\mathrm{B}$ agrees to share the costs. This is an important difference.

What is interesting about the case in question, that is carbon sink conservation, is that foreign states can benefit from the efforts by forested developing states to protect their forests without prior payment, since the carbon absorptive capacity of tropical forests is a public good. To be precise, the carbon sink function of tropical forests is a public good with the following properties: it is non-excludable (that is countries like Ecuador cannot control whose emissions will be sequestered by the 
forests) but its consumption is rival, which means if the emissions of A take up all the absorptive capacity of the forests there is nothing left for B. These properties make tropical forests as carbon sinks collective goods (rather than pure public goods). ${ }^{8}$ While pure public goods are non-excludable and non-rival in their consumption, collective goods are non-excludable but rival in consumption. This raises the obvious question, then, why the beneficiaries of developing countries' carbon sinks should share in the costs of preservation, since countries cannot choose not to benefit (unless a country stops emitting altogether which at this point in time seems technically impossible). Moreover, we seem to require much further argument for the claim that even indirect costs (such as the opportunity costs of not exploiting the oil in Ecuador's case) should be borne by benefitting developed states. Consider an analogous point from the cake example above: if A asked B to compensate him for missing an important job interview while baking the cake, we most definitely would not think that B had any obligation to compensate A for the forgone benefit of his future earnings.

In short, what the argument seems to require to get off the ground is a stronger connection between the beneficiaries and the costs which were accrued by the preserving party. One way of getting such a connection is to base the argument not on benefitting as such but on wrongful or unjust benefitting, which is an idea that Page (2012) and Butt (2014) have defended with regard to making the beneficiaries of historical wrongs/injustice pay. Another option would be to drop the benefitting aspect all together and to argue directly from historical responsibility. I will return to both these options below. Before doing so, however, it is worth pointing out a major problem with regard to the idea of benefitting that does the normative work in the standard argument.

As it stands the argument claims in (3) that 'the developed states of the global North (and their people) largely benefit from carbon sink conservation'. What this formulation entails however is that the benefit in question is forward-looking, which means that the duty to share in the costs of carbon sink conservation falls to those parties which do and will benefit from the very act(s) of preserving tropical forests. The problem with basing one's argument for cost-sharing on the prospective benefits from actual conservation is the obvious time-lag involved: if countries like Ecuador and Papua New Guinea decide not to exploit their rainforests and to actively preserve them for the benefit of higher carbon absorption, it is rather questionable whether the main beneficiaries of this policy are currently living people from the global North. In fact, considering the fact that the effects of climate change are and will continue to be most severe for extremely vulnerable people in developing countries, one could argue that the people who will most benefit from carbon sink conservation are future people in the developing world in poor and vulnerable circumstances. If the argument for paying for Ecuador's and Papua New Guinea's efforts to maintain their carbon sinks and to forgo development opportunities is based on benefits, then, it seems odd to assume that currently

\footnotetext{
${ }^{8}$ Public goods is the umbrella term. Pure public goods (i.e. non-rival and non-excludable goods) and collective goods (i.e. rival and non-excludable goods) are both forms of public goods. For a good discussion of this terminology see Armstrong (2015c, pp. 4-5) and Ostrom and Ostrom (1977).
} 
living people in the global North are the obvious payers. Moreover, if we really focus only on the benefits from carbon sink preservation it looks as if quickly developing and highly populated countries such as China and India should shoulder more of the burden than industrialised countries with smaller populations and decreasing emissions, despite the latter's historical responsibility. Again, this seems odd. In other words, if actual benefitting from current and future conservation does the normative work in the standard argument, the ones paying should be those who benefit most in the future, which in many cases will be either not born yet or amongst the most vulnerable to already existing harms from anthropogenic climate change. ${ }^{9}$

While it is possible to exclude the most destitute from the group of beneficiaries that have to pay for tropical forest preservation by adopting an ability-to-pay constraint, meaning that only those of the beneficiaries who can afford it have to pay towards carbon sink conservation, the underlying problems remains the same: the standard argument singles out the actual beneficiaries of better carbon sink conservation without any regard for the questions of who caused the problem and who benefitted from the emissions that led to a world in which carbon sink conservation is so important. Thus, if benefitting from conservation is the normative reason for sharing costs, it is quite likely that historically responsible, currently over-emitting industrialised countries who enjoy high resilience to climate changeinduced threats will not have to pay, or only very little. This observation leads us back to the two options for getting a better argument off the ground I mentioned before, namely to ground the argument either in wrongful benefitting in the past or in historical responsibility for the problem, i.e. the increased risks and harms associated with anthropogenic climate change. Both these options seem to establish the necessary link between developed countries and the costs in question.

The first option is to argue that the reason why (affluent) developed states have a duty to contribute towards the costs of carbon sink conservation is that they wrongfully benefitted from the emitting processes which lead to today's situation, in which forested developing countries have to preserve their forests rather than exploit their natural resources. Similar arguments in the broader context of sharing the burdens of climate justice have been presented by Page (2012) and Baatz (2013). However, the BPP is a controversial principle, even if it is limited to the idea of wrongful benefitting, which is an idea that in itself requires further elucidation (Heyward 2014; Butt 2014). Thus, I do not want to claim here that the BPP is necessarily a good way of justifying duties of cost-sharing. All I want to do is highlight the possibility of using a different conception of benefitting for salvaging the original standard argument. However, adopting such a view would obviously present a radical departure from the initial standard argument. In addition, if the arguments by Page, Baatz and others are correct, the idea of wrongful benefitting actually triggers a general duty to compensate the victims of global climate change and those most vulnerable to its future effects. Therefore, whether the argument from wrongful benefitting actually provides a direct argument for carbon sink conservation cost compensation is at least questionable, since it is primarily aimed

\footnotetext{
${ }^{9}$ Page (2016) makes a similar observation, calling it the 'climate policy-winners problem'.
} 
at disgorging wrongfully acquired benefits and redistributing these benefits to those who are most vulnerable.

Similarly, if the argument were based on the idea of historical responsibility what one would arrive at is a general argument for why those states that are historically responsible should bear significant parts of the costs of climate change mitigation and adaptation. That is to say, while historical responsibility might be a good reason for assigning remedial and compensatory duties, using the idea of historical responsibility changes the structure of the original argument, since benefitting plays no further role and carbon sink conservation seems only a particular instantiation of historically responsible states' duty to shoulder the (financial) burden of climate change mitigation. However, using historical responsibility for grounding duties of climate justice is not without controversy either, for instance because it is difficult to assign direct cause-and-effect relations, and because of the involved time-lag between emitting and resulting harms and risks. Thus, whether historical responsibility is indeed able to get a cost-sharing argument in the case of carbon sink conservation off the ground remains to be seen.

Either way, as my discussion in this section has shown, the straight-forward Beneficiary-Pays Argument fails to justify assigning duties to developed states to shoulder the costs of carbon sink conservation. While there exist two alternative ways of framing the argument, neither is without controversy and both would significantly alter the normative structure of the initial argument. Let us thus consider whether the Free-Riding Argument fares any better.

\section{The Free-Riding Argument}

Apart from going for straight-forward future benefitting in the interpretation of step (3) of the standard argument, one can also refer to the principle of fairness and the idea of wrongful free-riding via the definition of tropical forests (as long as they function as carbon sinks) as collective goods. This is the interpretation that Armstrong (2015c) goes for. ${ }^{10}$

According to Armstrong (2015c) tropical forests in their function as carbon sinks are collective goods, which benefit a lot of states and people outside the countries where they are located. Since people in developed countries reap part of the benefits of developing countries' costly efforts to preserve their tropical forests, the principle of fairness demands that developed countries bear a fair share of the overall costs. If they do not do so, developed states wrongfully free-ride. However, the reason for this is not simply that developed states benefit from a collective good, since that does not seem sufficient. Imagine you spend a lot of time and money on maintaining the flowerbeds in our inner courtyard. While I truly enjoy looking at the beautiful flowers and I even value your efforts, it seems that I don't owe you compensation for your work, since it was your free decision to maintain the flowerbeds. Thus, we need further reasons, which turn unobjectionable free-riding as in the flowerbed example into cases of wrongful free-riding. One way of doing that would be if you

\footnotetext{
10 Axel Gosseries (2004) presents a trans-generational free-riding argument in order to justify compensatory duties of climate justice for the descendants of historical polluters.
} 
and I both had an overarching duty to maintain the flowerbeds, which in our case would be a shared duty of global climate justice. However, as noted before, this is not the way the standard argument sets up the problem.

Consequently Armstrong (2015c, pp. 7-8) provides us with an example which is supposed to show under which conditions free-riding on somebody else's costly collective good provision is morally objectionable and triggers duties of fairness.

Poisoned Lake A lake spanning two countries sustains fishing industries upon which both depend. Tomorrow the government of country A discovers an underwater geyser, just on its side of the national boundary, which has started to belch out methane. Uncontrolled, the methane will soon destroy all of the fish which the lake currently provides (equally) to both countries. Placing a concrete cap on the geyser will be expensive, and the government of A asks the government of B to share in the costs.

(...) Whilst country B can refuse to share the costs of protection... it is hardly just for them to do so. To make the injustice still more apparent, we can stipulate that the reason it is necessary for country A to cap the geyser is that the fishing activities of both countries have disturbed it, and that the amount of concrete required to cap the geyser-hence the cost of the cap-is directly related to the incidence of fishing. In that case, for country B to refuse to contribute is still less defensible: the cost borne by A is imposed by an activity which both countries benefit from, and the scale of the cost increases in a linear fashion with the degree of benefits which country B (along with country A) extracts. ${ }^{11}$

Let us take a second to carefully unpack this example. In its initial form the poisoned lake example simply holds that since A and B both benefit from A's costly capping of the geyser, they should share the costs. ${ }^{12}$ However, it is not any kind of benefit that we talk about here but benefits 'upon which both depend'. Thus, if we were to change the example to a case in which no geyser exists but A develops a substance that allows tracing the fish in the lake more easily, so that A and B can both fish a lot more and more efficiently which benefits both their economies significantly (leaving environmental concerns for the sake of this example aside), the question is whether we still think it is unjust if B refuses to cover part of the development and deployment costs accrued by A. It seems that people will disagree on this. While A's actions clearly benefitted B, B never ask for the benefit and A might well have developed the substance without even thinking about B's benefits. While it is quite conceivable that B has good reasons to be grateful to A and thus to share in the costs, it is less clear that any obligations of justice and/or fairness have been triggered.

Think, for instance about the amount of ships that—while passing-benefit from lighthouses erected by an island state: the lighthouses might have been built with the

\footnotetext{
11 Emphasis in the original.

12 It is widely agreed in the literature that simply providing a public good based benefit is not enough for triggering duties; the provision of the benefit also needs to be efficient and cost-effective. For the remainder of the discussion on free-riding I take these conditions to hold.
} 
local fishermen and fisherwomen in mind, but they also benefit others. Do we therefore think all passing ships need to pay for part of the costs of erecting and maintaining the lighthouse $?^{13}$ One possible answer could be that by benefitting from the lighthouses which form part of an established practice of nautical collaboration, one automatically is liable for sharing in the costs (Rawls 1999, p. 96; Koltonsky 2014). However, another possible answer is to stress the benefit's non-excludable nature, which means that ships which have to take the route past this island have no choice but to see the light of the lighthouses (Cullity 1995). Therefore, no duty to share in the costs has been triggered.

It is worth noting, however, that part of what does the normative work in Armstrong's argument is not the simple fact of benefitting (or free-riding) from costly collective/public good provision, but that the benefit is (a) something all parties depend on, and (b) that without action by A existing benefits are severely threatened. Clearly, this is a very different normative situation, since the case changes from one of simple free-riding to one of being saved from disaster. Thus, in the poisoned lake example A does not simply provide a 'presumptively beneficial good' (Armstrong 2015c, p. 10), but A provides a necessary service for avoiding major harm to A and B. This is an important point to keep in mind,

In addition, Armstrong's assertion that one can simply make 'the injustice still more apparent' by introducing another normative dimension (i.e. shared causal responsibility) is odd, since this again changes the normative landscape of the example in question. In this case, it is no longer innocent free-riding which is at stake here but the idea that A and B both are to responsible (and possibly to blame?) for the dangers they face now. Thus, adding the idea of casual responsibility introduces a separate normative concern and it does not help to show why innocent free-riding on somebody else's costly collective good provision is morally objectionable. ${ }^{14}$ Therefore, let me leave historical responsibility for the time being aside and focus on the idea of free-riding as such.

As mentioned above, the case for wrongful free-riding seems to be strongest when the benefits in question are necessary for the cost-avoiding beneficiary. What this entails, however, is that if A were not to provide the good in question, B would suffer a major harm or major setback of interests. If that is what does part of the normative work, though, we have two problems when we want to apply Armstrong's free-riding argument to the case of tropical forest conservation in countries like Ecuador: first, there is no single provider of the necessary good (i.e. A alone cannot provide the benefit in question); second, the group of free-riding beneficiaries is large and diverse (i.e. there is no single B who benefits and does not share in the costs).

The first problem is that unlike in Armstrong's poisoned lake example (and also Armstrong's other example called Arborea) the collective good that is provided by individual states like Ecuador is in itself not enough to (a) make the risk of significant future harm due to the effects of anthropogenic climate change disappear

\footnotetext{
13 Gosseries (2004) uses a similar example.

14 For a discussion of innocent benefitting and when remedial duties are triggered see Barry and Wiens (2014).
} 
(as it would in the geyser example), and (b) secure a large enough quantity of the good so as to be able to say that all Bs (since there are more than one; see point below) definitely benefit from the provision of the good in significant ways. Naturally, if all forested states agreed to preserve their forests, this situation would change, but that means that part of the force of the argument seems to depend on whether carbon sink conservation is a collective commitment or a commitment by individual states.

The second problem is more worrisome. It reiterates the fact that there is no single B which benefits from A's actions, which implies that it is difficult to ascertain who benefits how much. Moreover, we again face the problem that it is prospective benefitting which presumably triggers the duty to share in the costs, which means that we once again might end up with an argument that identifies the 'wrong' payers, i.e. those countries which stand to benefit most from reduced climate change risks rather than chiefly historically high-emitting developed states. In order to make the argument stick with regard to the duty of developed states to pay for the costs of carbon sink conservation we have to revert to the idea of historical responsibility, which is probably precisely the reason why Armstrong tried to sneak it into his poisoned lake example.

The problem with this move is that it significantly alters the structure of the argument, since it is no longer only the free-riding which does the normative work: what seems relevant in the carbon sink protection case is that (a) developing states with tropical forests do not freely decide to maintain their sinks but they do so out of a sense of global climate justice (let's assume that is true), and (b) the only reason why these countries at all have to preserve all these sinks is that the global North largely caused anthropogenic climate change. Thus, the issue here does not really seem to be the benefitting but the fact that developing states are historically responsible and that the benefits they will gain were not voluntarily or accidentally created but because actions by the developed countries imposed obligations of justice onto countries like Ecuador and Papua New Guinea in a form they would not have had without the developed states' actions. It is in light of these further considerations that any benefits for the developed countries without compensation could be considered cases of wrongful freeriding.

Therefore, without contextualising and historicising the Free-Riding Argument it fails to deliver a plausible interpretation of the standard argument. Since we discovered similar problems with the Beneficiary-Pays Argument, it is fair to conclude that as it stands the standard argument proves insufficient for delivering its conclusion. What is more, as the discussion of the Free-Riding Argument has shown, it is worth asking why developing forested states at all have a duty to protect their entire carbon sinks. This is what I will do in the next section.

\section{Contextualising the Standard Argument: Historical Responsibility, Global Climate Justice and Non-compliance}

The criticism presented in the previous section questioned the validity of the argument from steps (1) through (3) in order to arrive at (4). As we saw, identifying the developed states of the global North as the payers in (4) seems to require some 
further assumptions, such as that these states benefitted wrongfully in the past or that they are historically responsible for the current situation and thus for the costs which developing forested states incur in their attempts to conserve their carbon sinks. Thus, in this section I want to critically examine whether assumption (1) that 'developing states with major tropical forests have a duty of justice to preserve these forests due to their status as a major global carbon sink, which is a collective good,' is the adequate starting point for the standard argument (or any other argument about burden-sharing in the context of carbon sink conservation). As I will argue, instead of taking the duty of developing states in (1) for granted we should ask (a) why such a duty exists, (b) why (if it exists) it should have the form and content that the standard argument claims, and (c) how the urgency and content of the duty (if it exists) is affected by historical, current and presumably future widespread noncompliance.

\section{Why do Developing Forested States Have a Duty to Preserve Their Carbon Sinks?}

Before answering the question of why certain states have duties to preserve their carbon sinks, it might be useful to get a clearer idea of the kind of duties that are commonly assigned to states in the global and climate justice literature. One relevant duty is, at least if one follows recent functionalist accounts of state legitimacy, every state's duty to meet its citizens basic needs and to realise its citizens' fundamental interests (Stilz 2009). On top of that, in order to legitimise the territorial possessions of states, we could argue that states have a duty to advance globally at least minimally just relations, such as respecting other states' right to self-determination (Nine 2012). In addition, we could argue for global and intergenerational duties of (climate) justice, for instance, that states and individuals should aim to avoid significant current and future harm, or the imposition of major risks of significant harm, if doing so is not overly costly. As part of this duty it is nowadays widely assumed that states have a duty to respect certain ecological limits and to be sensitive how their actions might interact with other agents' actions so as to avoid overconsumption of vital environmental resources (Blomfield 2014). While it is due to issues of uncertainty and fragmentation of cause and effect certainly difficult to precisely specify what kinds of actions are ruled out by one's global and intergenerational duties of (climate) justice, even such a vague formulation will give us a useful normative yardstick to operate with. ${ }^{15}$ All of these duties obviously apply to all states no matter whether developing or developed. So how does the developing states' duty to conserve their carbon sinks follow from this set of duties and which aspects might have been missing from the original standard argument?

From the viewpoint of developing forested states such as Ecuador and Papua New Guinea, the obvious place to start is the duty to meet their citizens' needs and realise their fundamental interests. This implies providing a safe and sustainable environment, which in turn includes carbon sink preservation. However, if it were

\footnotetext{
15 This is not to say that such a vague formulation would be without controversy, not at all. However, for the purpose of this paper I want to assume that certain duties of global and intergenerational (climate) justice exist, which seems to fit with the implicit commitments of the standard argument.
} 
possible to opt out of the global carbon cycle and if it thus were only about the citizens of Ecuador or Papua New Guinea, neither state would need to conserve all of their terrestrial carbon sinks (at least for reasons of climate change avoidance), as long as their green house gas (GHG) footprints stay within reasonable limits. In fact, Papua New Guinea's annual per capita GHG footprint is so small that the state could easily be carbon neutral and still exploit the majority of its rainforest resources. ${ }^{16}$ However, as we know no country can opt out of the global carbon cycle, so it is not up to states like Ecuador and Papua New Guinea to decide how much of their carbon sinks need to be preserved. Instead, as part of a global community of states, forested developing states seem to have a duty to contribute towards global environmental sustainability, even if it is difficult to substantiate what that necessarily entails.

Hence, in answer to question (a), we can note that as such the duty to protect their carbon sinks seems to be for developing forested states a contingent instantiation of their general duty of global climate justice to stay within certain ecological limits. However, what this means depends on what the state of the world is and how states and people have acted previously, since it is after all past over-emitting of GHGs which has caused anthropogenic climate change, so even if in the here and now all states emitted only within strict ecological limits, climate change would still be a serious issue and hence major carbon sink conservation, too. At the same time, of course, the extent to which all countries protect their carbon sinks changes the amount of available absorptive capacity, which in part determines the ecological limits within which states must stay. Therefore, it seems that we need a more indepth account of the relationship between competing normative claims to the use and/or protection of states' carbon sinks, since countries like Ecuador will stress their right to self-determination and sovereign control over their natural resources, while other states will stress the collective good function of carbon sinks. It seems plausible to assume, though, that there is no general duty for states to preserve all of their carbon sinks and that this is only a particularly strong version of states' general duty of global and intergenerational climate justice. If that is the case, we can move on to question (b).

\section{Why Should Developing Forested States Today Have the Specific Duty to Preserve all Their Carbon Sinks?}

According to our best scientific estimates, because of past and current GHG emissions the states of this world have to drastically lower their GHG emissions, protect their remaining carbon sinks and invest in large-scale adaptation measures. It is in this context that it seems plausible to hold that developing forested states like Ecuador and Papua New Guinea have a pressing duty of justice to protect their tropical forests. Moreover, we should probably consider this duty of justice to be global in scope, that is, it is a duty these states owe to all other states (and their citizens) as well as to their own citizens. Thus, in order to provide for their citizens basic needs and in order to secure for people around the world a healthy and

\footnotetext{
$\overline{16}$ Papua New Guinea's annual per capita emissions of $\mathrm{CO}_{2}$ are around 0.6 metric tons.
} 
sustainable environment, countries like Ecuador and Papua New Guinea have indeed strong reasons to maintain all their carbon sinks. At the same time, though, in order to protect their citizens as well as they can against the harms and risks associated with global climate change, which after all is not a process Ecuador or Papua New Guinea can stop on their own, both countries might have similarly strong reasons to exploit part of their tropical forests (and the resources found beneath it, as in the case of the Yasuni national park) in order to use the proceeds to protect their citizens as well as possible. If the account of states' duties I gave is correct, both these conflicting considerations draw on important duties states have. It thus depends on the specific context of the situation whether this conflict materialises and how it should be resolved. Therefore, it is not only the specific content of the duty to conserve one's carbon sinks that is context-dependent, it is also the duty's urgency.

After all, if developing forested states had a clear-cut duty to protect all their tropical forests asking for money in order to comply with this duty could be considered a case of unjust misconduct and 'ecological hostage taking'. ${ }^{17}$ The only reasons, however, why states like Ecuador might have the duty to protect their carbon sinks in the strong way specified, is that other countries have (a) emitted too much in the past, (b) continue to emit too much and (c) that Ecuador and Papua New Guinea have neither a way of excluding others from using their carbon sinks, nor a away of protecting themselves against the negative consequences of climate change (which was largely caused by others). ${ }^{18}$ This then leads us to the issue of noncompliance and how it should affect the way we see problem.

\section{How is the Urgency and Content of the Duty to Protect one's Carbon Sinks Affected by Historical, Current and Presumably Future Widespread Non-compliance?}

As I argued above, if we were to assume that forested developing states have duties of justice to conserve their terrestrial carbon sinks independent of the overall context, we would miss the fact that the historical over-emitting by some countries, paired with current non-compliance by those and other countries is the only reason why we nowadays are in a situation in which the conservation of virtually all terrestrial carbon sinks seems necessary for avoiding the worst sides of dangerous anthropogenic climate change. Countries like the US and UK seem to fail to discharge several (or possibly all three) of their abovementioned duties: (1) they fail to adequately protect their citizens' needs and interests by advancing utterly unsustainable policies, (2) they undermine the idea of globally just reciprocal relations by over-consuming and imposing severe risks on other people, as well as

\footnotetext{
17 The former German Minister of Economic Cooperation and Development Dirk Niebel objected to the Yasuni-ITTI precisely because he saw it as a case of ecological hostage taking. In the 'real' world, very few people agreed with Niebel.

18 To this you can add d) that a country like Papua New Guinea might want to raise its emissions, as part of its further development. Still, even if Papua New Guinea tripled its annual GHG emissions, it could easily use large parts of its terrestrial carbon sinks for other purposes (assuming that Papua New Guinea wouldn't burn its forests since that would set large amounts of carbon free; see the statistics in the introduction of this paper).
} 
by forcing states such as Ecuador and Papua New Guinea to adopt policies they would not have otherwise had to adopt; (3) states like the UK and the US obviously also jeopardise future people's survival and well-being, even though not doing so would in many cases not be overly costly. Even if we were to hold that states like the US and UK do possibly fulfil the first duty (i.e. meet their citizens' basic needs and fundamental interests), it seems that there is something normatively quite objectionable about Ecuador and Papua New Guinea having to discharge a certain duty (i.e. carbon sink conservation) and incur some costs because other states fail to adequately discharge their duties.

In this particular case it seems that Ecuador and Papua New Guinea are forced to take up the slack because other nations are not doing their part. However, this obviously raises the question of whether states such as Ecuador and Papua New Guinea do indeed have an obligation to take up the slack, considering that (a) other states are non-complying and (b) the only reason why we are in the current situation is other states' overconsumption (Hohl and Roser 2011). On top of that the states mentioned in sub-clause (a) and (b) are largely the same states (though not necessarily so), meaning that the ones responsible for the mess are also the ones who do not help to clean it up (or at least they do not help as much as they should). It does seem to be a perfectly feasible response by forested developing countries to call for major mitigation commitments by the historically responsible and thus far non-complying developed countries, before committing to any sort of costly carbon sink conservation program. ${ }^{19}$

If these arguments are sound, it seems at least questionable that Ecuador and Papua New Guinea have the duty to protect all their carbon sinks without any prior action by the historically responsible and currently non-complying states. If the duty to protect all one's carbon sinks indeed exists, under conditions of non-compliance its extent probably should be limited. That is, even if we assumed that states like Ecuador have a duty of justice to preserve all their carbon sinks, under conditions of widespread non-compliance and historical responsibility/non-compliance the onus to act first and to address global climate change clearly lies on non-complying developed states. While it is of course possible that forested developing states agree to preserving all their carbon sinks as part of a global climate agreement, in the absence of such an agreement, it seems questionable that a country like Ecuador or Papua New Guinea has the duty to preserve its carbon sinks, considering not only the non-compliance by others and their historical responsibility, but also the likelihood that the conservation actions by individual countries will most likely prove futile in the absence of serious and sustained action by others. ${ }^{20}$ This is not to say that under conditions of non-compliance states like Ecuador and Papua New Guinea have no duties if global climate justice whatsoever, all I claim is that it is not

\footnotetext{
19 As mentioned before another reason for choosing this policy response could be simply because nonconservation could prove more useful for generating revenues which can be invested in local adaptation and loss and damage recovery measures.

${ }^{20}$ One possible and important objection to this way of reasoning is that even if carbon sink conservation might not avoid future climate change altogether, it might help to stay below a crucial threhsold (e.g. a climate tipping point) which might be a strong enough reason to conserve anyway. In general, it would be wrong to assume that individual actions (by states or individuals) make no difference in the world. They do make a difference, just not necessarily a significant one.
} 
possible to assign countries like Ecuador a particularly strong duty to act unilaterally, if the need for this action is generated by justice-ignoring others and if the effectiveness of such action is dependent on better future action by currently and predictably continuingly non-complying others.

On top of that, the right to self-determination might provide us with a further reason to assume that under conditions of non-compliance, that is, in situations in which developed countries fail to commit to substantial mitigation commitments, countries like Ecuador and Papua New Guinea do not have a duty of justice to others to conserve all their carbon sinks (though they probably owe significant conservation to their own citizens, present and future). However, one could also argue that 'unilaterally' imposed climate change (i.e. climate change caused by developed states but affecting all states) undermines the right to self-determination of developing countries and that this is another strong reason why first the developed states have to do their fair share (i.e. mitigate radically and work towards fulfilling their three aforementioned duties) before states like Ecuador and Papua New Guinea have to make any sacrifices or incur any costs. On such a reading, tacking up the slack would be out of the question.

Overall then, the duties involved in settling the issue of carbon sink conservation might be more complex and diverse than first anticipated. Considering the fact that many developed states seem to be not only historically responsible but also noncomplying and thus imposing burdens on others, raises the question of whether we should not start by asking the question of what these states owe others as a duty of justice, prior to moving onto the question whether self-determining states such as Ecuador and Papua New Guinea owe others the conservation of their carbon sinks. This is not to say that such duties do not exist at all, but to start with these duties seems somewhat premature.

\section{Concluding Remarks}

While there is obviously a lot one can add, I think the discussion thus far has already shown that the duties the original standard argument alluded to are not as clear-cut as initially assumed. Both, the Beneficiary-Pays and the Free-Riding interpretation of the standard argument were shown to be problematic, pointing to the need to significantly revise the original argument. In addition, the paper gave several reasons why we should further contextualise our analysis of the ethics of carbon sink conservation, even if that does not make the analysis any easier. Whether states such as Ecuador and Papua New Guinea really do have a duty to act upon their duty of justice towards people in the developed world to protect their terrestrial carbon sinks is questionable, and so is the extent of these countries' duties of climate justice under conditions of widespread and persisting non-compliance. This is not the answer climate conscious philosophers hope for but it might help to shift the moral burden further onto rich over-emitting and non-complying developed states.

Acknowledgments Early versions of this argument were presented at the ECPR Joint Sessions of Workshops 2014 in Salamanca and the Political Theory Seminar at Queen's University Belfast. I am 
grateful to the attendees of those events for their helpful feedback. I also would like to thank Ed Page, Chris Armstrong, and an anonymous reviewer from Res Publica for a number of important comments on how to improve the arguments presented. Further thanks are due to my hosts at the Department of International Relations at the University of the Witwatersrand where I completed work on this project.

Open Access This article is distributed under the terms of the Creative Commons Attribution 4.0 International License (http://creativecommons.org/licenses/by/4.0/), which permits unrestricted use, distribution, and reproduction in any medium, provided you give appropriate credit to the original author(s) and the source, provide a link to the Creative Commons license, and indicate if changes were made.

\section{References}

Armstrong, Chris. 2015a. Climate justice and territorial rights. In Climate change and justice, ed. Jeremy Moss. Cambridge: Cambridge University Press.

Armstrong, Chris. 2015b. Against 'Permanent Sovereignty' over natural resources. Politics, Philosophy \& Economics 14: 129-151.

Armstrong, Chris. 2015c. Fairness, free-riding and rainforest protection. Political Theory. Early-view. doi:10.1177/0090591715594840

Baatz, Christian. 2013. Responsibility for the past? Some thoughts on compensating those vulnerable to climate change in developing countries. Ethics Policy and the Environment 16: 94-110.

Barry, Christian and David Wiens. 2014. Benefiting from wrongdoing and sustaining wrongful harm. Journal of Moral Philosophy. doi:10.1163/17455243-4681052

Blomfield, Megan. 2014. Global justice, natural resources and climate change. Unpublished PhD thesis, University of Bristol.

Boden, T.A., G. Marland, and R.J. Andres. 2010. Global, Regional, and National Fossil-Fuel CO2 Emissions. Carbon Dioxide Information Analysis Center, U.S. Department of Energy. doi:10.3334/ CDIAC/00001_V2010. Accessed February 92015.

Butt, Daniel. 2014. A doctrine quite new and altogether untenable': Defending the beneficiary pays principle. Journal of Applied Philosophy 31: 336-348.

Cullity, Garrett. 1995. Moral free-riding. Philosophy \& Public Affairs 24: 3-34.

Gibbs, Holly, Sandra Brown, John Niles, and Jonathan Foley. 2007. Monitoring and estimating tropical forest carbon stocks: Making REDD a reality. Environmental Research Letters 2: 1-13.

Gosseries, Axel. 2004. Historical emissions and free riding. Ethical Perspectives 11: 36-60.

Hohl, Sabine, and Dominic Roser. 2011. Stepping in for the polluters? Climate justice under partial compliance. Analyse \& Kritik 33: 477-500.

Horton, Bruce, Giordano Colarullo, Ian Bateman, and Carlos Peres. 2003. Evaluating non-user willingness to pay for a large-scale conservation programme in Amazonia: A UK/Italian contingent valuation study. Environmental Conservation 30: 139-146.

Heyward, Clare. 2014. Benefitting from climate geoengineering and corresponding remedial duties: The case of unforeseeable harms. Journal of Applied Philosophy 31: 405-419.

Koltonsky, Daniel. 2014. The principle of fairness, political duties, and the benefits proviso mistake. Journal of Moral Philosophy. doi:10.1163/17455243-4681060

NASA. 2011. New NASA map reveals tropical forest carbon storage. http://www.nasa.gov/topics/earth/ features/earth20110531.html. Accessed February 52015.

Nine, Cara. 2012. Global justice and territory. Oxford: Oxford University Press.

Ostrom, Vincent, and Elinor Ostrom. 1977. Public goods and public choices. In Alternatives for delivering public services, ed. E.S. Savas, 7-49. Boulder: Westview.

Page, Edward. 2012. Give it up for climate change: A defence of the beneficiary pays principle. International Theory 4: 300-330.

Page, Edward. 2016. Qui bono? Justice in the distribution of the benefits and burdens of avoided deforestation. Res Publica 22. doi:10.1007/s11158-015-9313-y.

Rawls, John. 1999. A theory of justice, Rev ed. Oxford: Oxford University Press.

Schuppert, Fabian. 2014. Beyond the national resource privilege: Towards an international court of the environment. International Theory 6: 68-97. 
Stilz, Anna. 2009. Why do states have territorial rights? International Theory 1: 185-213.

UN-REDD. About REDD and About REDD ${ }^{+}$. http://www.un-redd.org/AboutUN-REDDProgramme/tabid/ 102613/Default.aspx and http://www.un-redd.org/aboutredd/tabid/102614/default.aspx. Accessed February 12015.

Vanderheiden, Steve. 2014. Climate change and free riding. Journal of Moral Philosophy. doi:10.1163/ $17455243-4681046$ 